\title{
Coping and resilience: children's responses to online risks
}

\author{
Sofie Vandoninck, Leen d'Haenens and Katia Segers
}

\section{Theoretical background}

There is an impressive body of behavioural science research, beginning in the 1950s, which focuses primarily on '[w] hat makes a difference in the lives of children threatened by adversity or burdened by risk' (Masten and Powell, 2003, p 4). Exposure to risks is part of everyday life and potentially contributes to increased ability to cope with threats; however, children's resilience to risks varies, and some cope with adversity better than others (Smith and Carlson, 1997). Resilience, defined as 'positive patterns of adaptation in the context of risk or adversity', is considered one of the most complex and provocative aspects of human development (Masten and Gewirtz, 2006, p 24). Masten and Gewirtz (2006, p 24) define the concept of 'coping' as 'efforts to adapt to stress or other disturbances created by a stressor or adversity'. Interestingly, risk and protective factors can work together to enhance overall resilience (Coleman and Hagell, 2007, p 15).Very few studies focus specifically on resilience to risks in the online world, and also little work has been done on investigating whether the risks encountered offline also extend to the online world.

\section{Contextualising online risks: from risk to harm}

As children grow older and as their level of digital literacy increases, they are more exposed to all types of online risks (Livingstone et al, 2011). Psychological characteristics are related to the effect of online risks: children with more self-efficacy and more psychological difficulties, who are sensation-seeking, experience more exposure (see Table 16.1).

Exposure to risk, however, is not necessarily related to more harm. Despite their higher levels of exposure, older children, children from more affluent homes and children with high self-efficacy are frequently 


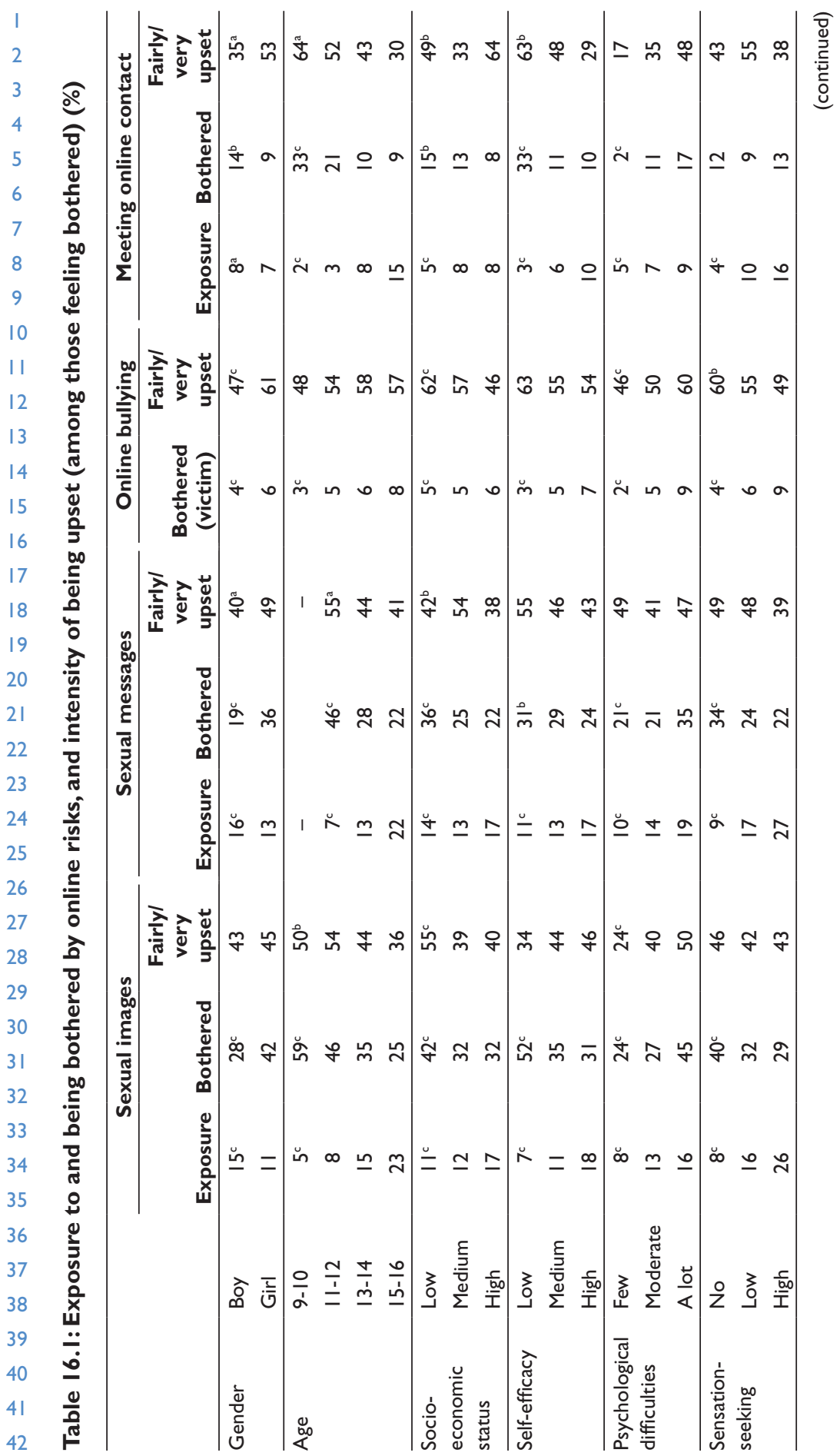




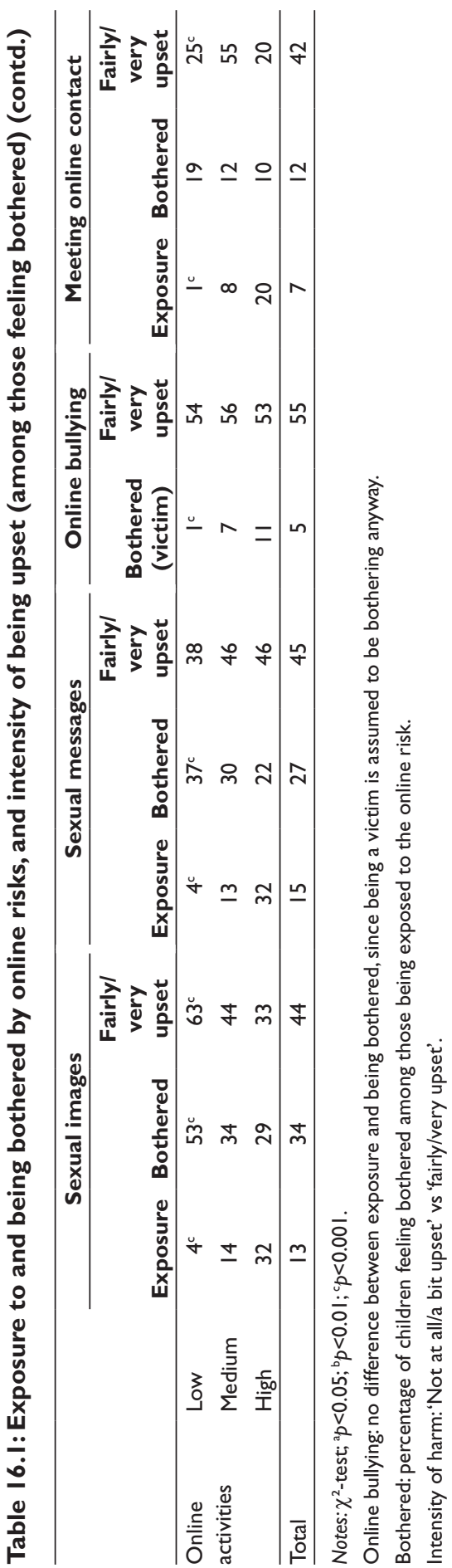


less bothered by sexual risks (seeing sexual images or receiving sexual messages) or offline meetings with online contacts. High sensation-seeking and a wide range of online activities also seem to increase children's resilience towards online sexual risks. Experiencing psychological difficulties may threaten the development of children's resilience to online risks: emotionally troubled children are subject to higher exposure to online risks and are more likely to feel bothered by the experience.Although boys more often see or receive sexual images and messages, girls are more sensitive about sexual risks.

Psychological characteristics have a particularly strong impact on a child's level of perceived harm, irrespective of the type of risk. Selfconfident children are more likely to recover from the experience immediately, while children with psychological difficulties may experience more intense, longer-lasting harm (that is, they are more upset.$\equiv$ re are some personal characteristics that are related to resilience to risk: sensation-seekers are more resilient to online bullying and $\mathbb{A}$ wider range of online activities seems to have a mainly positive impact on resilience to disturbing sexual images. Younger children are more intensely upset by sexual risks (both images and messages). Girls tend to find it more difficult to cope with contact risks (online bullying, sexting and meeting online contacts). Children from lower socioeconomic status families are more upset by online bullying. Overall, children with psychological difficulties manifest in the offline world are likely to be more vulnerable online, and children who are generally more resilient are likely to develop resilience to online situations.

Online bullying is the online risk that most upsets young people: more than half of the children who had been victims of cyberbullying said they were very or fairly upset by it. In relation to sexual risks, more children were upset after seeing sexual images than after receiving sexual messages. Horer, if child is upset seein sexull inage, the feeting is in contacts offline is less likely to produce negative feelings: among those children who felt bothered by the experience, the majority were only slightly upset. These findings illustrate why it is important to differentiate between exposure to risk and actual harm. While relatively many [[quite a few?]] $\equiv$ ng people come across sexual images and/ or receive sexual messages, these incidents cause less harm than being exposed to acts of online bullying. Adults tend to overestimate the risks related to meeting online contacts, since in most cases these meetings are pleasant experiences involving age group peers. Moreover, what adults might consider risky young people may perceive as opportunities. 


\section{Coping strategies: who adopts what strategy when encountering what risk?}

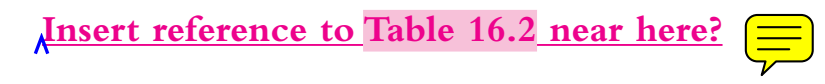

\section{Fatalistic response}

Children can respond in passive, rather fatalistic ways, hoping simply that the problem will go away, or stop using the internet for a while. The former group may be upset for a short time, and any harm is not substantial or long term, or they may feel indifferent, accepting that sometimes they will encounter unpleasant things. One in four of those bothered by an experience hope the problem will go away, and this reaction is related less to specific sociodemographic or psychological characteristics. Deciding to stop using the internet can be interpreted as ignoring the problem without eliminating the actual cause, and involves missing online opportunities or puilding resilience. This strategy is more common among younger children, lower socioeconomic status children, children with little self-efficacy or with psychological difficulties, young people who engage in only a few online activities and those who are more intensely upset.

Younger children are more likely to adopt a fatalistic reaction to unwelcome sexual images. Boys and children from higher socioeconomic status families more often hope simply that the problem will go away. Girls, lower socioeconomic status children, those with psychological issues and the less active internet users more often decide to go offline for a while, a more radical decision that indicates that they feel more upset. Indeed, those feeling upset to more intense degrees stop using the internet more often. Boys receiving unwelcome sexual messages online are more likely to do nothing and wait until the problem goes away; girls are more likely to react by going offline for a time. Children with low self-confidence, and older children, are more likely to stop using the internet. Children upset by sexting are more likely to turn off their computers for a while. Among victims of online bullying, psychologically troubled children and those more upset and upset for longer by the experience are more likely to respond fatalistically. Girls more often simply hope that the problem will disappear without intervention.

These findings indicate that more vulnerable groups are more likely to use a strategy that may further reduce their capacities for resilience and online opportunities. However, about seven in ten children who went offline for a while following an upsetting experience indicated this strategy was 'helpful', although in this case it is important to 


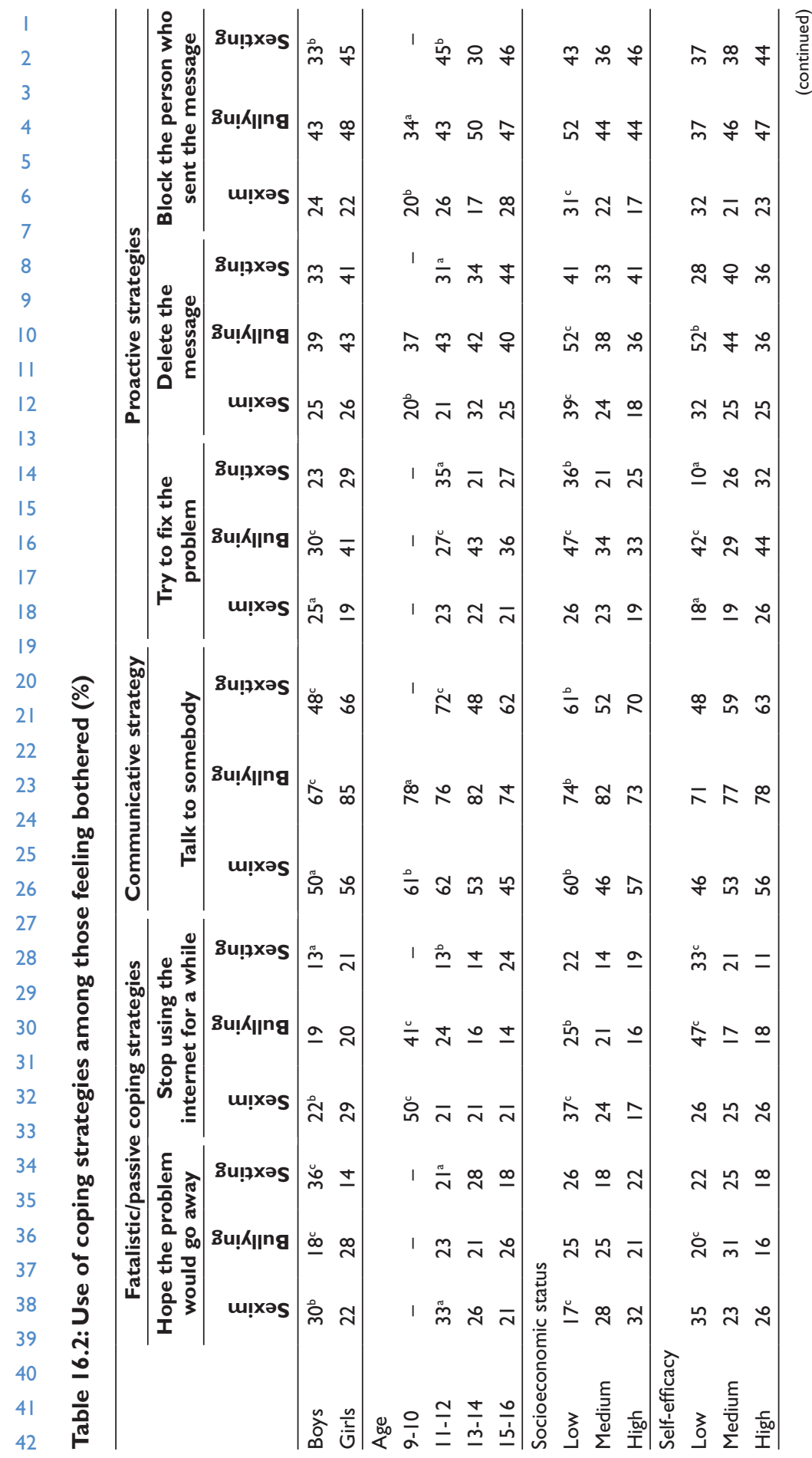




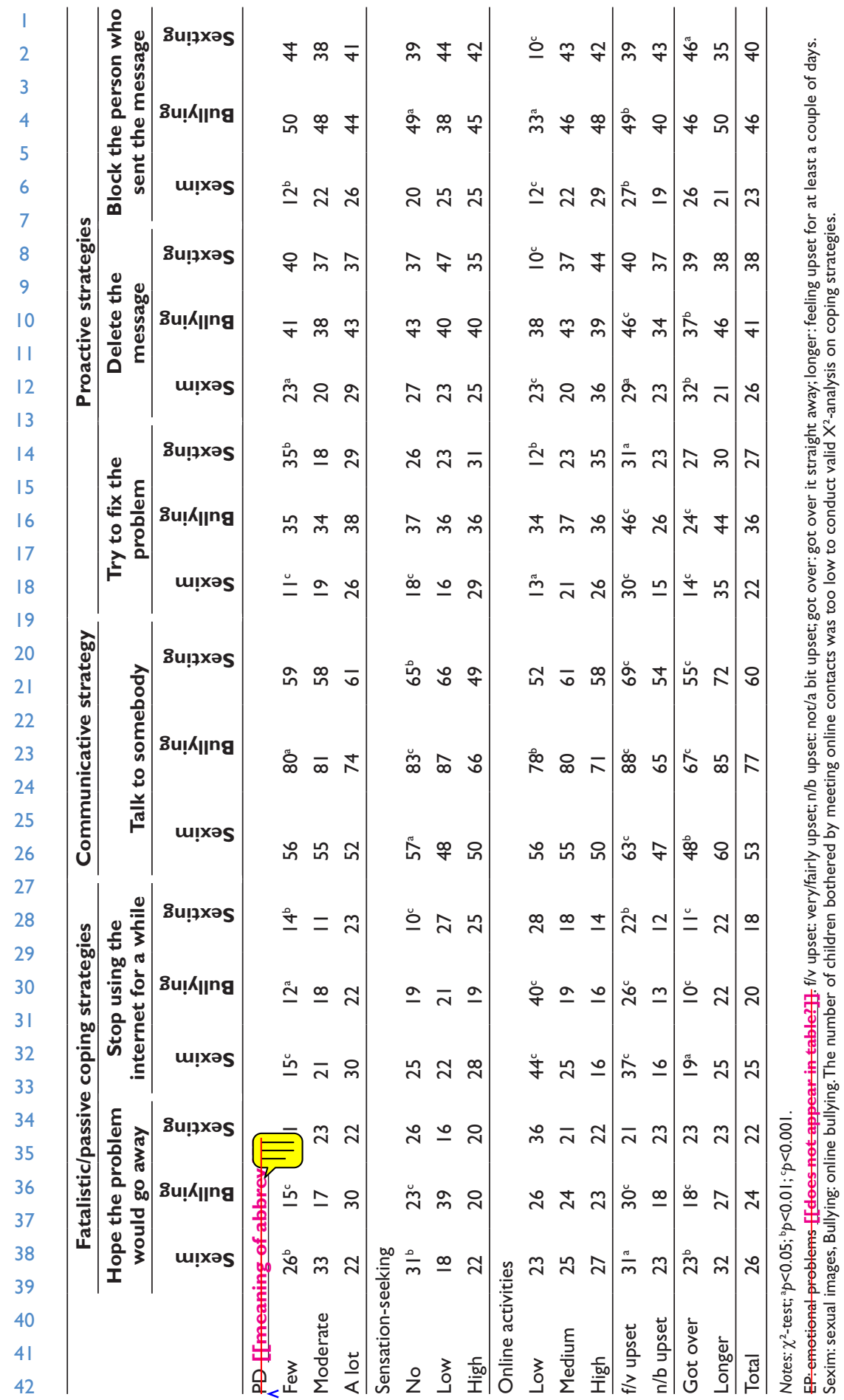


understand that 'helpful' refers to lack of further exposure to online risks during that time.

\section{Communicative response}

Children can adopt a communicative approach, seeking social support and talking to someone. For all online risks, children prefer to talk to their peers (63-68 per cent) or to parents (48-54 per cent). Only a few children turned for advice to teachers (4-10 per cent) or professional childcare workers (2-4 per cent).

Regardless of the type of online risk, girls, children not interested in sensation-seeking and those experiencing more intense feelings of being upset tend to be more communicative. About half of children talk to someone about an upsetting sexual image and one in six discuss the receipt of an unwelcome sexual message. Younger children are more likely to talk to someone when they feel bothered by sexual risks. Children from lower socioeconomic backgrounds tend to talk to someone when they are bothered by sexual images, while children from more affluent families will talk to someone about sexting-related problems.Among victims of online bullying, 77 per cent report talking to somebody about this. Interestingly, children who engage in fewer digital activities are more likely to talk to someone about being bullied online.

These findings might be an indication that awareness-raising campaigns that emphasise communicative coping strategies are having an impact. Communicative strategies are broadly adopted by members of sociodemographic groups identified as vulnerable (girls, younger children, lower socioeconomic status children). However, children with psychological difficulties or low self-efficacy - identified as most vulnerable - are no more likely to talk about their negative experiences than children with no psychological issues.

\section{Proactive response}

Children who are proactive are regarded as displaying the best adaptation (most resilience) to adversity, because their actions are intended to reduce or eliminate harm in the future. Greater intensities of feeling upset promote a greater tendency for some children to try proactively fo fix the problem. Although this reaction is not limited to the more resilient groups, the willingness to tackle problems independently is stronger among children with high self-efficacy. This suggests that selfconfidence is a key component of greater resilience. Internet-specific 
coping strategies, that is, deleting messages or blocking senders, require minimal digital skills. Hence, as expected, the number of a child's online activities is positively related to these coping strategies. Our findings also confirm that if the feeling of being upset is strong and persistent, this motivates the child 'to fix' the problem.

Children are more likely to respond proactively to being bothered (upset) by sexual images if they use the internet for a wide range of activities. Trying to fix the problem is a more likely response among more resilient groups, such as boys, self-confident children and sensation-seekers, as well as those experiencing more intense harm. Online proactive coping strategies are also common among lower socioeconomic status children. Thus, a proactive response to upsetting sexual images is not limited to the more resilient groups. Also, the child's level of online activities is again related positively to a proactive response to unwelcome sexual messages. Self-confident children are more likely to try to fix problems, but more vulnerable groups, such as younger children and children from lower-class families, also favour this approach.There is no straightforward relationship with other personal characteristics. Children are most proactive when the victims of bullying online, and the number of online activities is positively related to the strategy of blocking the senders of upsetting messages.

There is a self-reported success rate of around 80 per cent for deleting messages and blocking senders, which are perceived as very effective strategies to cope with sexting. For victims of online bullying, blocking the sender is more effective (78 per cent) than simply deleting the message (58 per cent). In the case of experiences of unpleasant sexual images, it is more helpful to delete the content (82 per cent) than to block the source or sender (71 per cent). Overall, the strategy adopted depends on the risk at stake.

\section{Coping strategies: predictive factors}

To provide a more complete picture of the relative predictive value of sociodemographics, psychological difficulties (emotional, conduct and peer problems) and the range of online activities for children's coping strategies, we conducted linear regression analyses for three of the four online risks (seeing sexual images, online bullying and receiving sexual messages) ${ }^{1}$ (see Table 16.3). In Table 16.3, empty cells refer to non-significant beta values. Emotional, conduct and peer problems were added separately to the regression model. The relative impact of these different types of psychological problems varies across different coping strategies and different online risks. For example, in the case of 


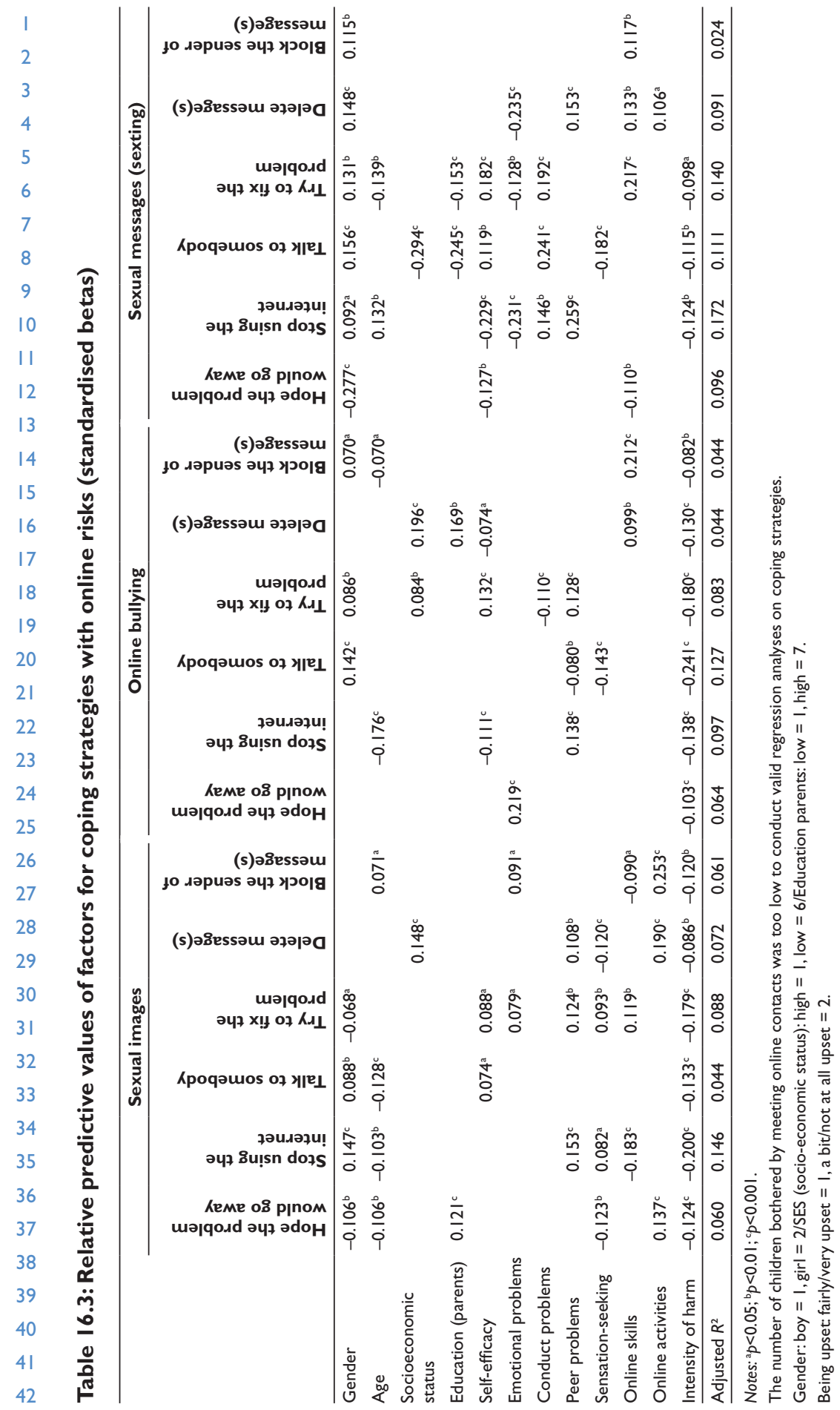


online bullying, it is peer problems that show the main influence on children's coping reactions; in the case of sexting, children's strategies are explained by a broader range of psychological difficulties. These nuances are better captured by looking at emotional, conduct and peer problems separately rather than psychological problems combined.

\section{Sexual images [[level hd}

Children who feel very upset when confronted by sexual images are more likely to respond in some way - passively, communicatively or proactively. Girls, younger children, children who have problems with peers, sensation-seekers and children with few online activities more often take the route of going offline for a time following an upsetting experience with sexual images. Adoption of a proactive problemsolving strategy increases children's resilience and is more common among self-confident children and children who are very active online. Also, sensation-seekers and those who experience peer problems are more likely to look for some solution to their problem. The use of specific online coping strategies, such as deleting or blocking messages, increases with the range of children's online activities. Girls, younger children and very self-confident young people prefer a communicative approach.

\section{Online bullying}

More intense feelings of being upset have a strong impact on the whole range of children's responses to online bullying. Children with higher self-efficacy are more willing to try to fix the problem and not to stop using the internet. The children most vulnerable to online bullying are children with peer problems, low self-efficacy and younger children: all are more likely just to stay offline for a period. Experiencing peer problems s linked to being a boy, to coming from a more afluent hes to responding proactively to problems. The children these attributes seem to experience serious harm, which apparently motivates them to look for a (long-term) solution to bullying. Selfconfident children are also proactive at dealing with bullying. Deleting messages and blocking senders of upsetting messages happens more often among children who are highly tive online. Those who prefer a communicative response following an experience of bullying online tend to be girls, low sensation-seekers and children with no peer problems. 


\section{Sexual messages (sexting)}

Experience with sexual messages produces the response in boys of hoping that the problem will go away, in sints stop using the computer and talk to someone or be proactive. Girls, and children with low self-efficacy, more conduct problems and more peer problems, are more likely to decide to go offline for a while after a sexting incident. It is noticeable that older children and children with no emotional problems often adopt a fatalistic approach to sexting. Presumably, the more resilient children go offline for short periods, while those groups less able to cope may stop using the internet for much longer. Although girls, children with conduct problems and children with no emotional problems are more likely to abandon the internet for a time, they are also more motivated to look for solutions. Also, children engaged in a broad range of online activities, higher socioeconomic status children and younger age groups tend to respond proactively. The group most vulnerable to harm from sexting are children with low self-confidence: this group more often stops using the internet and less often searches for solutions. Internet-specific coping strategies (deleting messages and blocking senders) are practised more often by girls, children with no emotional problems, children with peer problems and, as might be expected, children who are more active online (who engage in more activities). These findings indicate that the likelihood of using online coping strategies increases with the intensity of distress from the experience, a certain state of mind and mastery of the necessary skills.

\section{Conclusion}

Exposure to risk does not necessarily result in harm, and not every risk is equally upsetting. Some online risks, such as seeing sexual images, provoke mainly minor negative responses. Other risks, such as meeting online contacts offline, are perceived mainly as opportunities and are rarely upsetting for those involved. In order to understand the negative effects of online risks, it is crucial to take account of the child's understandings and characteristics. Children reporting more psychological difficulties, particularly those with low self-efficacy and emotional problems, are more likely to be upset by the risks they encounter. For each type of risk, individual characteristics (gender, age, online activities) play a definite role in the intensity of the harm that children feel following exposure to that risk. Our results are indicative of a type of 'Matthew effect' (in which the rich get richer and the poor get poorer), in that those children who experience more difficulties 
coping with offline risks seem to find it more difficult to cope with online risks.

In tackling the problem of online risks in relation to young people, it is essential that educators and policymakers know what young people actually perceive as most risky and upsetting. From the four risks discussed in this chapter, online bullying has the strongest negative impact. However, it is the online risk that engenders the most proactive and communicative coping responses. Young people who encounter disturbing sexual images are less inclined to look actively for a solution to the problem. Online problem-solving coping strategies, such as deleting unwelcome messages or blocking contacts, are much more common if children are upset by the risks, and young people feet extremely upset tend to adopt more proactive or communicative coping strategies. This suggests that children are able to build, resilience through the use of different strategies when confronted with something that upsets them. However, it should be borne in mind that some children are significantly less likely than others to be able to respond adequately. Across all risks, the 'more vulnerable' children will often stop using the internet for a time, which then slows their progress up the ladder of digital opportunities (see Chapter 6).

Our findings show that more than half of children (including less resilient groups such as girls and primary school children) talk to someone about online problems, which implies that awareness-raising efforts already in place are playing a positive role. However, we need other initiatives to encourage children with psychological difficulties and/or low self-efficacy to talk about the online risks they encounter and the harms they suffer. As more and more children perceive talking to someone to be an acceptable coping strategy, those providing the support could become key agents in the transition from using communicative to applying proactive strategies.

\section{Notes}

${ }^{1}$ The number of children bothered by offline meetings with online contacts is too small for a valid regression analysis.

\section{References}

Coleman, J. and Hagell, A. (eds) (2007) Adolescence, risk and resilience: Against the odds, Chichester: John Wiley \& Sons Ltd. 
I Livingstone, S., Haddon, L., Görzig, A. and Olafsson, K. (2011) Risks 2 and safety on the internet:The perspective of European children. Full findings, 3 London: London School of Economics and Political Science.

4 Masten, A.S. and Gewirtz, A.H. (2006) 'Vulnerability and resilience 5 in early child development', in K. McCartney and D. Philips (eds)

6 Blackwell handbook of early childhood development, Oxford and Carlton: $7 \quad$ Blackwell Publishing, pp 22-43.

8 Masten,A.S. and Powell,J.L. (2003) 'A resilience framework for research, 9 policy and practice', in S. Luthar (ed) Resilience and vulnerability: 10 Adaptation in the context of childhood adversities, New York: Cambridge II University Press, pp 1-25.

I2 Smith, C. and Carlson, B.E. (1997) 'Stress, coping and resilience in I3 children and youth', Social Service Review, vol 71, no 2, pp 231-56. 